\title{
O Programa Minha Casa Minha Vida \\ e as Tecnologias de Microcrédito: Contribuições para uma Agenda de Pesquisa
}

http://dx.doi.org/10.21527/2237-6453.2019.47.120-135

Recebido em: $17 / 7 / 2016$

Aceito em: 17/12/2018

Lucas Ambrózioํ, Lauro Gonzalez²

\begin{abstract}
RESUMO
Dada a natureza e objetivos do Programa Minha Casa Minha Vida é iniciada uma tentativa de identificação de potenciais de aperfeiçoamento a partir das inovações de crédito abordadas pela literatura de microfinanças. Por meio de estudo de caso da modalidade Entidades, demonstra-se que grande parte dos mecanismos apontados pela literatura de microfinanças e que estão previstos na legislação do Programa encontram óbices para sua execução. As técnicas de pesquisa utilizadas envolveram a coleta de dados e análise de resultados do Programa, cotejados a partir de entrevistas a diversos atores governamentais e da sociedade civil envolvidos na instituição do Programa. Esta análise empírica fundamenta a apresentação de uma agenda de pesquisa entre microfinanças e políticas de habitação.
\end{abstract}

Palavras-chave: Programa Minha Casa Minha Vida. Microcrédito. Análise de políticas públicas. Política habitacional. Financiamento.

\section{MINHA CASA MINHA VIDA PROGRAM AND MICROCREDIT TECHNOLOGIES:} CONTRIBUTIONS TO A RESEARCH AGENDA

\section{ABSTRACT}

The improvement and financial sustainability of the Minha Casa Minha Vida program are challenging issues. In this fashion, we analyze the potential sinergy between housing public policies and Minha Casa Minha Vida in particular and microfinance credit innovations. The analysis focused Entidades-modality inside PMCMV and was based on document's research, primary data collection and interviews with bureaucrats and beneficiaries. aiming at examining the potential proximity to microcredit. The results pointed to obstacles that have to be circumvent in order to materialize synergies. In addition, there is room for a new research agend involving microfinance and housing public policies.

Keywords: Minha Casa Minha Vida. Microcredit. Public policy analysis. Housing policy. Financing.

\footnotetext{
${ }^{1}$ Doutorando em Administração Pública e Governo pela Fundação Getúlio Vargas de São Paulo. Mestre em Ciência Política pela Universidade Federal de São Carlos. Analista de Políticas Públicas e Gestão Governamental da Prefeitura de São Paulo. lucasambrozio@yahoo.com.br

${ }^{2}$ Doutor em Economia de Empresas pela Fundação Getúlio Vargas de São Paulo. Professor da Fundação Getúlio Vargas de São Paulo. lauro. gonzalez@fgv.br
} 
O Programa Minha Casa Minha Vida (PMCMV), criado em 2009, visa a gerar mecanismos de incentivo à produção e à aquisição de novas unidades habitacionais pelas famílias com renda de até dez salários mínimos. O desafio inicial era coordenar diversos programas habitacionais que estavam dispersos em diferentes pastas do Executivo federal, buscando abordá-los de modo mais amplo, enfatizando projetos de interesse social (RODRIGUES, 2013), além de criar, por meio de incremento de governança, capacidades estatais compatíveis com o alto grau de prioridade da política na agenda governamental (LOUREIRO; MACARIO; GUERRA, 2013).

Questões relacionadas à sustentabilidade econômico-financeira foram relegadas a segundo plano em um primeiro momento, entretanto, diante do cenário fiscal que se desenha para os próximos anos, trata-se de discussão fundamental para continuidade do Programa. Uma das problemáticas de fundo para este artigo relaciona-se à elevada inadimplência (mais de 20\%) da chamada faixa 1 do PMCMV, na qual se enquadram as pessoas que ganham até $\mathrm{R} \$ 1.600,00$. Os atrasos são extremamente elevados, tanto comparados às operações tradicionais de crédito habitacional quanto às outras faixas do próprio PMCMV. Acreditamos que isto possua relação com a tecnologia de crédito desenhada para o Programa. A hipótese é que há pouco diálogo destas tecnologias com outras sobre crédito e pobreza, como as de experiências de microcrédito.

O PMCMV busca financiar imóveis para beneficiários de baixa renda e, por conseguinte, excluídos dos mecanismos tradicionais de crédito oferecidos pelo sistema financeiro geral. Trata-se, portanto, de serviço financeiro (crédito) a ser oferecido para a população relativamente pobre e excluída, sobre a qual há escassas informações ou histórico de crédito, além de poucas garantias.

Tal quadro de desafios nos remete diretamente aos encontrados em estudos sobre microcrédito (AGHION; MORDUCH, 2010). A partir da premissa de aproximação potencial dos desafios de financiamento do PMCMV aos de programas de microcrédito, buscaremos responder às seguintes perguntas: i) Quais as características da atual tecnologia de crédito empregada no PMCMV?; ii) Que aspectos dela se relacionam aos apontados pela literatura de microcrédito?. iii) Quais têm sido seus maiores obstáculos de efetivação? Cumpre mencionar que uma tecnologia de crédito pode ser definida como um processo integrado envolvendo três etapas: análise de crédito, monitoramento e cobrança (CAOUTTE; ALTMAN, 2008). O estudo restringiu-se à fase 2 do Programa Minha Casa Minha Vida, vigente de junho de 2011 a março de 2016.

O trabalho estrutura-se da seguinte forma: a próxima seção aborda a literatura disponível sobre habitação e microcrédito, ressaltando os pontos comuns entre ambos, fundamentalmente os desafios de financiamento das ações e focalização (atingir os mais pobres). A seção seguinte discute a metodologia do estudo. A seção na sequência apresenta as características do Programa, ressaltando a tecnologia de crédito atualmente empregada. A seguir são analisados os resultados dos dados coletados e das entrevistas. As considerações finais sumarizam a contribuição do trabalho e sugerem pontos em aberto como oportunidades de estudos futuros. 


\section{REVISÃO DA LITERATURA}

\section{Política de habitação: breve histórico da problemática do financiamento}

A preocupação com a habitação popular surge no contexto da entrada das políticas sociais na agenda governamental nos anos 30 , mas a primeira agência só foi instituída em 1946. As principais características da política eram subsídios indiretos, como a construção em terrenos doados por prefeituras, garantia de baixas taxas de juros e financiamentos de longo prazo, entretanto a política não se sustentou devido à falta de aportes permanentes, ao controle dos recursos e perda de capital investido. Diante de um contexto inflacionário, o desempenho destas iniciativas foi muito baixo (AZEVEDO, 1988).

Em 1964 é criado o Banco Nacional de Habitação - BNH. A justificativa econômica era de estímulo à poupança, ao mercado de trabalho e ao desenvolvimento da indústria de material de construção. Para garantir as fontes de financiamento, o BNH tinha como base o Sistema Financeiro Habitacional - SFH - que captava recursos de poupança compulsória, pelo Fundo de Garantia do Tempo de Serviço - FGTS - e voluntária, por meio do Sistema Brasileiro de Poupança e Empréstimo - SBPE. Os depósitos do FGTS eram constituídos por $8 \%$ dos salários dos trabalhadores formais. Já o SBPE destinava-se ao financiamento das classes média e alta (AZEVEDO, 1988; BONDUKI, 2009; LOUREIRO; MACARIO; GUERRA, 2013).

$\mathrm{O} \mathrm{BNH}$ obteve relativo sucesso quanto ao número de moradias impulsionadas, mas seus resultados sociais foram pífios. Favoreceu, sobretudo, as classes de maior poder aquisitivo, obtendo grande fracasso em proporcionar acesso à população mais pobre (AZEVEDO, 1988, 2002; BONDUKI, 2009). Diante de um contexto autoritário, é importante ressaltar que o processo decisório das políticas de habitação foi extremamente centralizado e contou apenas com a participação de grupos empresariais (LOUREIRO; MACARIO; GUERRA, 2013).

No início dos anos 90 a instituição dos programas de habitação buscou parcerias com organizações comunitárias locais. Apesar da obrigação dos Estados e municípios de criarem um fundo com tal finalidade, o próprio governo federal não instituiu um fundo federal para a política habitacional. Assim, os programas dependeram de recursos provisórios, o que fragilizou o financiamento da política (AZEVEDO, 2002). Ressalta-se nesse momento, a busca da articulação da política de habitação com os entes federativos e grupos da sociedade civil.

No governo FHC ocorreu a criação do Sistema Financeiro Imobiliário, com objetivo de financiar programas de habitação por meio de recursos de caderneta de poupança e do FGTS. O SFI foi inspirado em modelos norte-americanos e sua grande inovação advém da alienação fiduciária, com o próprio imóvel sendo a garantia da operação. Neste sistema, as taxas de juros e os prazos de financiamento são fixados por meio de contrato sem a presença do Estado. O grande problema deste sistema é que, mais uma vez, houve dificuldade de inclusão das pessoas de baixa renda, e foi direcionado majoritariamente para as classes média e alta (BONDUKI, 2009). 
Foi ainda no governo FHC que ocorreu a promulgação da Lei $n^{\circ} 10.257 / 2001$, que estabelece o Estatuto da Cidade, marco legal orientador para as políticas habitacionais elaboradas posteriormente. No início do governo Lula foi instituído o Ministério das Cidades e buscou-se colocar em prática estratégias de integração da política habitacional com outras de desenvolvimento urbano. Foram criados diversos órgãos colegiados e instâncias de participação, que subsidiaram a elaboração do Plano Nacional de Habitação (PlanHab).

Em termos de fontes de financiamento, houve ampliação de recursos por meio da combinação do FGTS e de formas de subsídio. Em seguida, no ano de 2005, o ConseIho Monetário Nacional obriga os bancos a investirem em financiamento habitacional a partir de uma percentagem de seus recursos em poupança, Resolução n $460 / 2005$, que também trouxe consequências para a ampliação de recursos do Fundo para subsídios habitacionais, ampliando o alcance aos mais pobres (LOUREIRO; MACARIO; GUERRA, 2013).

Devido ao então contexto de crise financeira (subprime), em 2008, e com objetivo econômico de política anticíclica foi criado o PMCMV. Neste caráter híbrido, de política anticíclica e habitacional residem, para alguns pesquisadores, as maiores virtudes e as maiores ambiguidades do Programa. Para Krause, Balbin e Neto (2013), o Programa responderia mais aos interesses do mercado do que aos princípios e estratégias definidos para a política de habitação, expressa pelo PlanHab. Esta tensão sempre esteve presente no interior do governo, mais especificamente no interior do próprio Ministério das Cidades (MCidades) e ao longo do tempo (SILVA, 2014).

O PMCMV, logo após a sua criação foi incorporado ao Programa de Aceleração do Crescimento e "se de um lado implicou a subordinação dos objetivos sociais da população de baixa renda, por outro, trouxe vantagens significativas ao torná-la prioridade na agenda governamental" (LOUREIRO; MACARIO; GUERRA, 2013), trazendo sucessivos incrementos orçamentários. Apesar de a política ter sido desenhada fortemente pelos altos dirigentes do governo federal e pelos empresários da construção civil, algumas demandas sugeridas no momento anterior da formação da política habitacional foram contempladas, como a inclusão da população de renda de até três salários mínimos, que compõem 80\% do déficit habitacional no Brasil (CAIXA ECONÔMICA FEDERAL, 2013).

\section{O Microcrédito}

O que atualmente denomina-se microfinanças surge como uma forma de quebrar o círculo vicioso da pobreza a partir de soluções e práticas inovadoras que superem os obstáculos dos problemas informacionais e reduzam os custos de transação. Segundo Gonzalez, Piza e Garcia (2009), é possível afirmar que as diversas experiências de microfinanças no mundo tendem a combinar um conjunto de inovações que ganharam grande repercussão com o Grameen em Bangladesh e seu programa de microcrédito. Com base em Morduch (1999), as inovações principais do microcrédito são: 1) empréstimos em grupo, 2) uso agente de crédito, 3) empréstimos progressivos, 4) frequência de pagamentos e 5) foco nas mulheres. Os itens 1, 2 e 5 são os mais relevantes aos propósitos deste estudo, como será mais bem explorado. 
Os empréstimos em grupo podem ser definidos como arranjos feitos por indivíduos que não dispõem de garantias tradicionalmente demandadas pelo sistema bancário. Essas pessoas formam espontaneamente um grupo cujo objetivo é a obtenção de empréstimos. Cada membro do grupo recebe determinado valor e, simultaneamente, garante os empréstimos dos demais. Assim sendo, em caso de inadimplência de um dos membros, os demais devem pagar a parcela correspondente, sob pena de não receber mais créditos.

Assumindo que cada tomador de crédito de um grupo detenha melhores informações sobre os demais tomadores do que o banco ou instituição de microcrédito, os efeitos para inadimplência esperada serão benéficos pelo fato de haver seleção (screeening) e monitoramento por parte dos pares (VARIAN, 1990).

Em termos empíricos, Moh'd Al-Azzam, Carter e Sudipta (2012) sugerem que o monitoramento e a pressão dos pares, além dos laços sociais existentes entre os membros dos grupos, têm efeito positivo sobre o pagamento, ou seja, reduzem a inadimplência. Por tal raciocínio muitos estudos sobre os efeitos dos empréstimos em grupo recorrem ao conceito de capital social, como uma linha de análise importante. Por exemplo, em Feigenberg et al. (2011), o capital social define-se a partir das interações entre os tomadores de empréstimos, com os dados mostrando que quanto maior a interação, menor a inadimplência.

A segunda inovação é a utilização do chamado agente de crédito, que é o profissional responsável pelo levantamento de dados sobre tomadores, principalmente novos empreendedores ou grupos, acompanhamento e auxílio a clientes, emissão e análise de relatórios técnicos e recuperação de crédito de tomadores inadimplentes. $O$ agente de crédito é o principal responsável pela inserção do microcrédito em uma determinada comunidade e tem papel importante para que o crédito alcance os mais pobres.

Um agente de crédito altamente produtivo chega a ter, em média, 300 clientes, o que permite à instituição credora auferir certo ganho de escala. Além disso, com a maior proximidade entre o agente e seus clientes, recupera-se uma das essências das operações de crédito tradicionais, qual seja, a construção de relacionamento de longo prazo entre credor e devedor, com potencial impacto sobre os níveis de inadimplência. Do ponto de vista empírico, Agier (2012) analisa o caso específico de uma instituição de microcrédito no Brasil e encontra evidências acerca dos benefícios associados à presença dos agentes, sobretudo ligados ao processo de seleção dos clientes. $O$ agente de crédito tende a passar boa parte de seu tempo próximo aos clientes tomadores, muitas vezes residindo nos arredores ou na própria comunidade da clientela, reforçando os elos e permitindo maior acompanhamento da própria carteira e auxiliando as famílias com o planejamento financeiro.

Por fim, uma das características do microcrédito é o foco nas mulheres. O primeiro argumento que justifica este direcionamento relaciona-se a combater o viés sexista do sistema financeiro, em muitos mercados, e ao papel desempenhado pela mulher na família e na sociedade, o que contribui fortemente para a redução da pobreza. O segundo argumento refere-se ao conceito de empoderamento (empowerment) das mulheres. É possível entendê-lo como o aumento da autonomia e da legitimidade das mulheres, perante o lar e a sociedade. Acredita-se que as mulheres possuem mais prudência na administração dos recursos do que os homens. 


\section{METODOLOGIA}

É adotada, preponderantemente, uma postura interpretativista, que considera que os fenômenos devem ser entendidos no seu ambiente social, por meio dos significados subjetivos e intersubjetivos que os indivíduos atribuem a eles. Em relação ao método empregado, considerando ser este um primeiro trabalho de uma agenda de pesquisa, utilizaremos a análise indutiva por meio de estudo de caso.

As técnicas para coleta de dados foram baseadas em entrevistas, documentos e dados oficiais sobre o programa. As entrevistas foram gravadas e se basearam em roteiros semiestruturados, desenvolvido a partir do referencial teórico e da análise documental. Especificamente, houve análise prévia de portarias e instruções normativas ministeriais referentes ao Programa, bem como de seus planos e relatórios disponibilizados pelos órgãos do governo federal. Ocorreu também prospecção de dados sobre o funcionamento do PMCMV junto a Caixa Econômica Federal (CEF), o principal agente operacional e financeiro do Programa. Assim, com múltiplas fontes de coleta de dados buscou-se trazer novos dados sobre o funcionamento do Programa, a partir de análises de sua dimensão normativa e positiva (dados de execução do Programa e relatos dos entrevistados).

Diante dos objetivos do trabalho vê-se, especificamente, no Programa Minha Casa Minha Vida - Entidades (PMCMV-E) uma oportunidade de estudo de caso e de teste de hipóteses sobre alguns princípios de microcréditos aplicados ao Programa. É, assim, a modalidade do Programa que mais se aproxima em potencial dos objetivos e tecnologias empregadas nas experiências de microcrédito. O PMCMV-E conta com recursos do Fundo de Desenvolvimento Social (FDS), com o Ministério das Cidades sendo o gestor da aplicação dos recursos e o responsável pela seleção das propostas encaminhadas pelas entidades. A CEF cumpre o papel de agente operador do FDS e agente financeiro. Há ainda espaço para a inclusão de agentes fomentadores/facilitadores, que podem ser os governos subnacionais, as companhias de habitação popular e órgãos similares, além de outras entidades e associações da sociedade civil.

Foram entrevistados dirigentes da Caixa de três diferentes níveis envolvidos diretamente na efetivação do PMCMV e do PMCMV-E, a saber: Diretoria de Habitação da Caixa, Gerência Nacional de Entidades Urbanas e Gerência de Clientes e Negócios. Também foram feitas entrevistas estruturadas com lideranças de entidades participantes do PMCMV-E (movimentos sociais de moradia).

\section{ANÁLISE DO FUNCIONAMENTO DO PMCMV}

\section{Fontes de Recursos e Estratégias de Crédito}

O PMCMV divide-se em Plano Nacional de Habitação Rural - PNHR - e no Plano Nacional de Habitação Urbana - PNHU. Este último conta com recursos oriundos do Fundo de Garantia do Tempo de Serviço - FGTS - Fundo de Arrendamento Residencial - FAR - Fundo de Desenvolvimento Social - FDS - e com Oferta Pública de Recursos - OPR. Estes três últimos mecanismos são utilizados para financiar as operações de beneficiários com renda familiar de até $\mathrm{R} \$ 1.600,00$ (Faixa 1, que envolve as famílias de menor renda do Programa), como é possível visualizar no Quadro 1. 
O PMCMV-E é uma modalidade dentro da Faixa 1. No Quadro a seguir apresenta-se as diferenças e o número de unidades habitacionais contratadas até 12/11/2014 (somente pela Caixa, não contando a fatia do PMCMV operado por outros agentes financeiros, em torno de $10 \%$ do total). Em geral, os aportes via Oferta Pública de Recursos são para custear os subsídios diretos oferecidos aos beneficiários.

No caso do PMCMV-E, cabe às entidades intermediar as relações com as famílias beneficiárias, reunindo a comunidade e organizando os trabalhos e o planejamento das atividades, além da indicação de responsáveis técnicos pelas obras. Os beneficiários devem possuir renda familiar de até 3 salários mínimos e a prestação do financiamento é fixada em $5 \%$ da renda familiar bruta, com prestações de no mínimo 25 reais e máximo 80 reais. Para as Faixas 2 e 3 as prestações podem ser bem maiores. Cabe destacar que o PMCMV-E representou a reestruturação do Programa Crédito Solidário, criado em 2005, mas que só começou a sair do papel em 2007. Embora diferentemente deste, que exigia a devolução total do empréstimo em 20 anos, o PMCMV-E subsidia grande parte dos projetos. Assim, as famílias pagam apenas uma parte dos valores ao longo de 10 anos (DO LAGO, 2011). As garantias ao agente financeiro no PMCMV-E advêm da alienação fiduciária e em caso de impossibilidade de constituição de garantia real individualizada há a aplicação da responsabilidade solidária (como nos empréstimos em grupo das experiências de microcrédito).

Quadro 1 - Modalidades do PMCMV, fontes de recursos e número de unidades contratadas pela Caixa até 12/11/2014

\begin{tabular}{|l|l|l|l|l|}
\hline Modalidade do PMCMV & Renda das famílias & $\begin{array}{l}\text { U.H. } \\
\text { contratadas }\end{array}$ & Percentagem & $\begin{array}{l}\text { Fundo/fonte } \\
\text { financiamento }\end{array}$ \\
\hline Faixa 1 (PMCMV-Entidades) & Até 1.600 reais & 50.811 & $1,62 \%$ & FDS e OPR \\
\hline Faixa 1 (restante) & Até 1.600 reais & 1.142 .317 & $36,46 \%$ & FAR e OPR \\
\hline Faixa 2 & Entre 1.600 e 3.100 reais & 1.466 .850 & $46,82 \%$ & FGTS e OPR \\
\hline Faixa 3 & Até 5.000 reais & 337.336 & $10,77 \%$ & FGTS \\
\hline Habitação Rural & Até 60.000 reais anuais & 135.702 & $4,33 \%$ & OPR \\
\hline TOTAL & & 3.133 .016 & & \\
\hline
\end{tabular}

Fonte: Elaboração própria a partir de dados fornecidos pela Caixa.

A diversidade de fontes de recursos à disposição do PMCMV possibilita o aumento dos subsídios, diminuindo as barreiras de entrada para contratos de financiamento habitacional, não havendo necessidade de que as famílias façam aporte inicial. Além disso, os fundos e as ofertas públicas de recursos complementam as garantias para as tomadas de crédito com os agentes financeiros, o que viabiliza a oferta de crédito habitacional com baixa taxa de juros. Segundo dados do Ministério do Planejamento (MPOG, 2013), o PMCMV responde por $21,4 \%$ do volume total de crédito habitacional no Brasil. O PMCMV engloba desde ações de subsídios quase totais (podendo chegar a mais de 95\% do valor do imóvel na Faixa 1) até ações cujo subsídio relaciona-se diretamente à redução na taxa de juros.

Quadro 2 - Benefícios do PMCMV segundo faixa de renda familiar (famílias urbanas)

\begin{tabular}{|l|c|c|c|}
\hline & Faixa 1 & Faixa 2 & Faixa 3 \\
\hline Subsídio para Habitação de Interesse Social & $\mathrm{X}$ & & \\
\hline
\end{tabular}




\begin{tabular}{|l|l|l|l|}
\hline Subsídio em financiamentos & $\mathrm{X}$ & $\mathrm{X}$ & \\
\hline Fundo garantidor & $\mathrm{X}$ & $\mathrm{X}$ & $\mathrm{X}$ \\
\hline Barateamento do seguro & $\mathrm{X}$ & $\mathrm{X}$ & $\mathrm{X}$ \\
\hline
\end{tabular}

Fonte: Elaboração própria.

No Programa como um todo os municípios (em geral) fazem o cadastro, seleção e indicação da documentação das famílias à Caixa. Esta, por sua vez, irá conferir a pré-análise da documentação, referente ao atendimento dos requisitos necessários, fazendo sua aprovação ou rejeição. A Caixa também é a responsável pela contratação das construtoras que farão as obras, bem como por todo o gerenciamento e acompanhamento dos contratos. Cabe também aos municípios e Estados a apresentação de contrapartidas como a doação de terrenos, a integração do local à rede de serviços públicos, a provisão de equipamentos públicos, a desoneração tributária do empreendimento e a adequação deste aos instrumentos previstos no Estatuto da Cidade. No caso do Programa Minha Casa Minha Vida-Entidades a pré-seleção é feita pela entidade, que também discrimina no projeto como será feita a aquisição do terreno e a execução das obras.

Além da citada diversidade das fontes de financiamento, há pelo menos outras duas características centrais para explicar a expansão do Programa. A primeira é o alto grau de flexibilidade e diversidade das articulações presentes no Programa, seja de modalidade para modalidade, seja dentro de uma mesma modalidade. Assim, o PMCMV assume formas de articulação que permitem a participação de vários atores, mas também apresenta estruturas para operacionalizar-se mesmo sem adesão de alguns deles. Ou seja, se os governos estaduais podem participar dos arranjos, por outro lado sua não adesão não impede que o Programa se materialize.

No PMCMV-E, as construtoras podem ou não participar (dado que é possível a produção direta pela entidade ou contratação de construtoras), assim como os Estados, que podem ou não oferecer contrapartidas. Confere, pois, grande capacidade de adaptação à realidade político-econômica de cada localidade, dando viabilidade institucional ao Programa e diminuindo possíveis pontos de veto/obstáculos. É um desenho de programa que engloba alta capacidade política em seu arranjo de instituição de políticas públicas (GOMIDE; SILVA; PIRES, 2014).

A segunda característica é a centralidade do agente operacional e financeiro, a Caixa. Este agente é o grande articulador e instaurador do Programa, é o único ator que sempre se relacionará diretamente com todos os atores, na Faixa 1, seja qual for o arranjo. Ademais, trata-se da instituição financeira líder em financiamento habitacional no Brasil e que conta com estrutura e expertise para lidar com moradia para a população de menor renda. São 72 Superintendências Regionais e Gerências de Habitação com grande capilaridade em todo território nacional.

\section{O processo de crédito}

Por processo de crédito entende-se as tecnologias de crédito utilizadas no Programa, composta pela análise, monitoramento e cobrança. Para as Faixas 2 e 3 (de 1.600 a 5.000 reais) a seleção dos beneficiários é feita diretamente pelo agente operacional, com critérios e mecanismos similares às operações tradicionais de financiamento habitacional. É realizada análise Siric - Análise de Risco de Crédito - para verificar a capaci- 
dade de pagamento do beneficiário. Diferentemente da Faixa 1, é preciso não possuir restrições creditícias. Segundo dados da Diretoria Habitacional da Caixa, o índice de inadimplência nas Faixas 2 e 3 é próximo da média dos financiamentos habitacionais em geral.

Na Faixa 1 do Programa um ator importante são as prefeituras. São elas que, em geral, enviam seus projetos e firmam os convênios com o MCidades e com o agente operacional. Os governos estaduais também podem participar, na maioria das vezes como cofinanciadores do projeto, dando o aporte adicional aos valores federais ou viabilizando garantias, terrenos ou infraestrutura. Existem, aqui, categorias do Programa de acordo com o tamanho do município e os custos de produção habitacional na região. Atendidos os requisitos nacionais, como renda e não participação em outro programa habitacional, bem como as prioridades estabelecidas pelo Programa, relativas à composição social da família, as prefeituras e governos estaduais podem ter regras próprias para atenção e distribuição das unidades.

Especificamente no PMCMV-E, a primeira etapa do Programa começa com a habilitação das entidades por parte do Ministério das Cidades, que avalia as capacidades das entidades em conjunto com a Caixa. A categorização das entidades é feita segundo critérios de demonstração de qualificação técnica e social por meio da capacidade de mobilização da entidade.

A Caixa verifica a documentação e os projetos apresentados pelas entidades e encaminha ao Ministério das Cidades. Na fase posterior, são recebidos os projetos de construção e a listagem das famílias indicadas pelas entidades. Os projetos são selecionados com base no atendimento dos requisitos técnicos definidos pela resolução do Conselho Curador do Fundo de Desenvolvimento Social, pelos requisitos sociais definidos pela Lei $\mathrm{n}$ - 11.977/09 (que prioriza mulheres, portadores de necessidades especiais e residentes em área de risco/desabrigados). A seleção também é limitada à disponibilidade de vagas do Programa, que são definidas preliminarmente pelo governo federal.

Na Faixa 1 o contato com as famílias é feito pela entidade organizadora (no caso do PMCMV-E) ou com a prefeitura (na Faixa 1 geral). A inadimplência dos empreendimentos é controlada pelo agente financeiro por meio de um sistema de cobrança com atraso maior que 30 dias, 60 dias e 90 dias, neste último já passível de execução. $A$ cobrança das prestações é feita via telemarketing. Embora formalmente seja possível a retomada dos imóveis por inadimplência, na prática ela só ocorre pelo uso indevido, venda/aluguel ou ocupação por outro que não seja o beneficiário que assinou o contrato. Já nas Faixas 2 e 3 a retomada por inadimplência é comum.

O acompanhamento na fase de construção dos empreendimentos é feito pelo agente operacional e financeiro, que avalia a execução das etapas do projeto e vai liberando os recursos. No caso PMCMV-E, quando a entidade executar a construção direta o agente financeiro antecipa os repasses, haja vista a limitada capacidade financeira das entidades. No acompanhamento do período posterior à construção há apenas operações de ouvidoria referentes à má qualidade estrutural dos imóveis e ao descumprimento das normas de uso do imóvel. No Gráfico 1 são apresentados dados de inadimplência do Programa, calculados a partir do número de contratos com atrasos de prestações em mais de 90 dias no ano de 2014. 
Gráfico 1 - Evolução recente da taxa de inadimplência no PMCMV (contratos operados pela Caixa) e no total de contratos do Sistema Nacional de Financiamento Habitacional

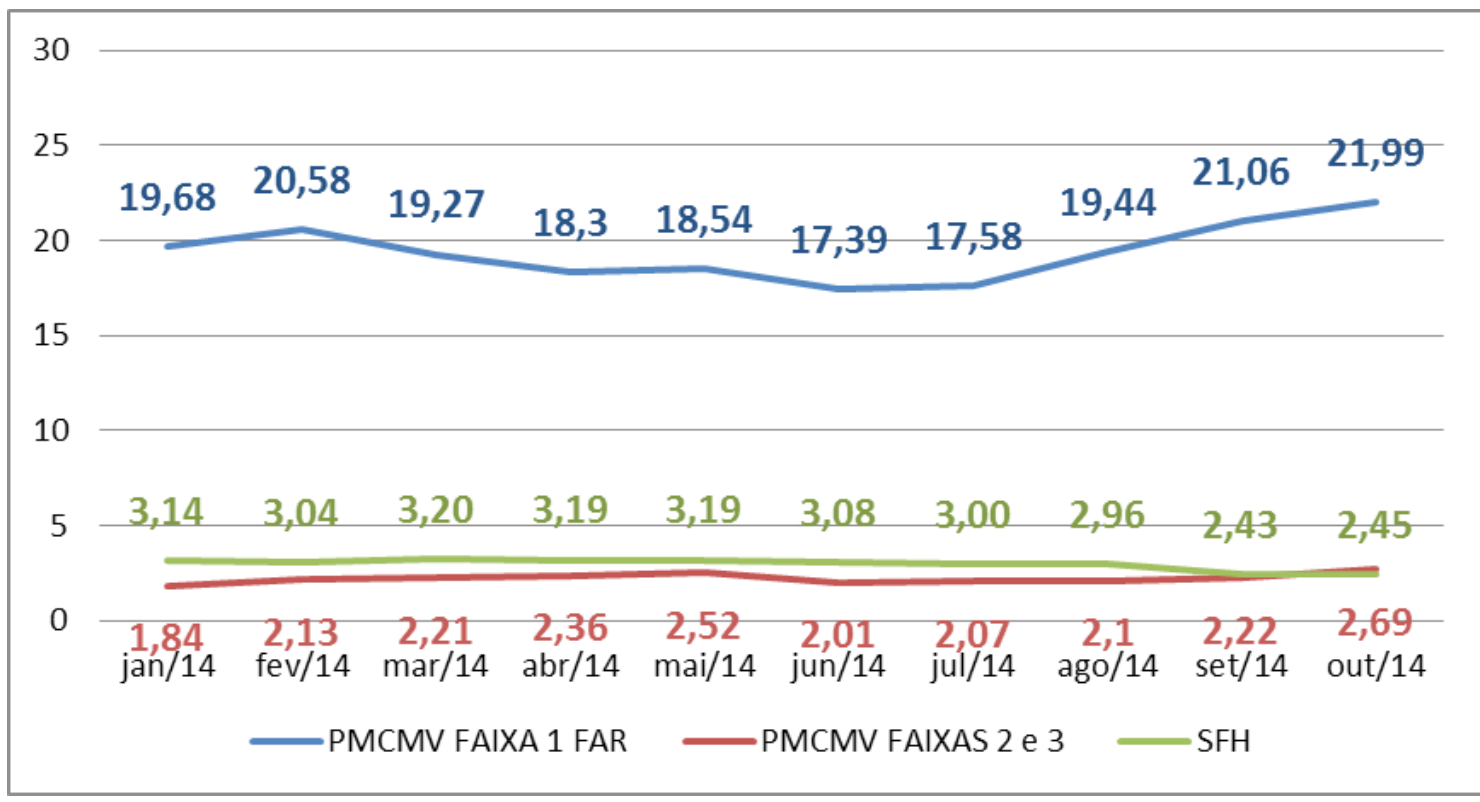

Os contratos com mais de 90 dias de atraso são aqueles passíveis de execução. A taxa de inadimplência das Faixas 2 e 3 do Programa tem sido menor que as do mercado de crédito habitacional. A mesma eficiência de controle da inadimplência, no entanto, não se estende para a Faixa 1, pelos motivos que veremos adiante, que justificam a estratégia de baixo monitoramento dos pagamentos na Faixa 1.

\section{ANÁLISE DE DADOS}

É possível afirmar que o PMCMV é relativamente bem avaliado pela literatura pertinente no que se refere a sua capacidade de financiamento e de articulação institucional (BONDUKI, 2009; KRAUSE; BALBIN; NETO, 2013; LOUREIRO; MACARIO; GUERRA, 2013; MARQUES; RODRIGUES, 2013). Ele foi eficaz em engajar o governo federal, que historicamente atuou de forma limitada em matéria de política habitacional, além de criar diversos arranjos e modalidades possíveis para ampliar a oferta de moradia para a população de menor renda.

O processo de crédito apresentado, no entanto, precisa ser aprimorado. Um potencial de aperfeiçoamento nesse sentido seriam as inovações do microcrédito, anteriormente citadas. Em que pese o fato de o foco da pesquisa recair sobre eventuais tecnologias de microcrédito aplicadas ao PMCMV, é possível identificar vários outros desafios durante o estudo, sobretudo nas entrevistas. Estes desafios podem ser organizados em três grandes eixos:

Eixo I: financiamento (aumento dos recursos disponíveis: pela oferta e pela diminuição da inadimplência) 
A. Análise da real capacidade e condições de pagamento das famílias: para além do atual cruzamento de dados do Cadastro Único (Cadúnico), da Rais (Relação Anual de Informações Sociais, do CadMut (Cadastro Nacional de Mutuários) e do FGTS.

B. Monitoramento dos pagamentos, controle da inadimplência e cobrança.

C. Expansão crescente da demanda em um contexto fiscal mais restritivo: hoje entidades, governos subnacionais e construtores estão mais preparados para expandir a oferta, mas como garantir mais financiamento?

Eixo II: participação social e fortalecimento do PMCMV-E

A. Acompanhamento das famílias pelo agente financeiro e pelo poder público: contato contínuo para o período posterior à entrega dos empreendimentos.

B. Aumentar a participação social no redesenho da política: ambiente favorável a ajustes e inovações no PMCMV.

C. Estímulo à organização da entidade: aumentando sua capacidade de mobilização social e trabalho no período posterior à obra.

D. Desestímulo e barreiras para a atuação de entidades que não cumprem a lógica de atuação do Programa (entidades com sérios problemas de accountability e lisura).

E. Aumentar a troca de informações entre o agente operador e as entidades do PMCMV-E, além da adoção de mecanismos já existentes na lei, como o repasse de bônus de adimplência para as entidades e uso do aval solidário nos projetos de financiamento (desafio comum ao Eixo l);

Eixo III: incremento da infraestrutura dos núcleos habitacionais

A. Reduzir o tempo de construção, principalmente nas unidades da Faixa 1 e desenvolver capacidades técnicas em atores participantes.

B. Integração dos empreendimentos à cidade e à rede de serviços públicos.

Os desafios do Eixo III distanciam-se do objetivo deste artigo e não serão analisados. De maneira geral, tanto o Eixo I quanto o Eixo II trazem à tona fatores ligados às inovações do microcrédito descritas anteriormente. Por exemplo, o uso de agentes de crédito poderia ser importante fator mitigador de risco de crédito, reduzindo a assimetria de informação por meio de um maior contato com os beneficiários, tanto antes como durante a vigência do contrato de crédito. Ou ainda, a adoção de mecanismos de empréstimos em grupo poderia contribuir para resolução dos problemas de falta de garantia, com potenciais efeitos benéficos para inadimplência. Por fim, o foco nas muIheres tende a trazer efeitos positivos em termos de administração do crédito em prol da família.

No caso do PMCMV-E, em 2014 pela primeira vez um número de unidades habitacionais solicitadas pelas entidades é superior à cota de unidades disponíveis, o que aumenta a importância de buscar novas fontes de financiamento, inclusive aquelas ligadas ao pagamento dos financiamentos por parte dos beneficiários, entretanto o controle da inadimplência apareceu como fator bastante secundário nas entrevistas realizadas. 
A inadimplência da faixa 1 do ponto de vista financeiro não tem relevância nenhuma. O custo de você cobrar e administrar estes contratos é muito maior do que se você tivesse zero de inadimplência. (...) Ou seja, a decisão de se cobrar mensalidades é uma decisão muito mais política, de afastar-se da ideia de doação, que historicamente mostra-se muito perniciosa, do que, realmente, a necessidade desse dinheiro retornar (Entrevista com dirigente $X$ da Caixa, realizada em 6/11/2014).

A fala anterior remete ao desafio de monitoramento e cobrança na Faixa 1 do Programa. Acreditamos que o uso de agentes de crédito, nos moldes descritos para as experiências de microcrédito, poderia promover maior proximidade entre PMCMV-E e beneficiários, viabilizando na prática mecanismos adequados de monitoramento e cobrança. Como já mencionado, os resultados empíricos são bastante eloquentes em termos de redução de inadimplência por baixo custo. Além disso, a ideia de que a mensalidade cobrada seja meramente uma decisão política, conforme a fala transcrita, tende a diminuir o incentivo para pagamento, na medida em que o beneficiário percebe que não se trata de uma "operação de crédito", que implica a adesão a regras de pagamento, sob pena de ter o nome "sujo" ou ser excluído temporariamente do mercado de crédito. $O$ agente de crédito mitiga o risco de inadimplência por tornar convincente a ideia de que as prestações devem ser pagas, a despeito dos sinais muitas vezes contraditórios ligados a uma prestação muito baixa.

Como está, prepondera uma situação indesejável, em que os recursos não retornam para o Fundo e nem as entidades conseguem acessar o bônus de adimplência, cuja obtenção está associada à adimplência de todas as famílias. A Caixa, entretanto, não repassa as informações para que a entidade possa desempenhar esse trabalho e consequentemente receba recursos por isso. Todas as entidades ouvidas disseram ter tido em algum período problemas com inadimplência de seus moradores. Conforme já mencionado, a inadimplência da modalidade Entidades do programa é hoje superior a $20 \%$.

Hoje o programa já prevê o bônus de assiduidade, mas nós nunca pagamos. E nós nunca pagamos, não só por culpa da entidade. Acredito que em uns $10 \%$ das entidades poderíamos até ter logrado isso, só que para a entidade cobrar eu tinha que passar para ela quantas pessoas estavam devendo e o nome das pessoas. Aí começou uma questão jurídica: quebra de sigilo, aí a gente não podia passar. Se a gente não pode passar, como a entidade pode saber quem ela vai cobrar? Isso ficou muito tempo aqui na Caixa, nós até questionamos: por que eu não posso fazer com a entidade se eu tenho contrato com empresa de cobrança terceirizada? De repente a gente faz um documento para a entidade dizendo que isso é sigilo, que ela não vai poder falar essas informações (Entrevista com dirigente $Y$ da Caixa, realizada em 12/11/2014).

Adicionalmente, no desenho atual do programa, não há identificação da real capacidade de pagamento das famílias, o que impede a cobrança de prestação mais calibrada. Na prática, para toda a Faixa 1, seguindo a lógica das regras atuais, há forte incentivo ex-ante (antes do pagamento das prestações) para os beneficiários pagarem o valor mínimo, no caso do PMCMV-E, R\$ 25,00. Ademais, ex-post perde-se uma oportunidade de, por meio do monitoramento, ajustar o valor da parcela à evolução de renda da família. 
Uma vez mais, o uso de agentes de crédito poderia contribuir para dar maior compatibilidade entre o valor da prestação e a renda dos beneficiários, tornando a prestação sensível à renda, possibilitando diminuição na participação atual do subsídio. Vale mencionar que não se trata de eliminar o subsídio, mas sim utilizá-lo de maneira socialmente mais justa, com os recursos economizados podendo ser revertidos para o próprio PMCMV.

Até o momento o PMCMV não aproveitou as oportunidades que poderia ter (ao representar um arranjo governamental de grande destinação de recursos para a política habitacional) ao criar mecanismos que condicionassem os repasses ou estimulassem maior interlocução federativa e a participação da sociedade mediante fóruns de participação e controle social. Muitos já existem, mas foram enfraquecidos. Assim, os fundos e canais escolhidos para o financiamento do Programa têm como característica alta maleabilidade na alocação e a baixa participação decisória dos governos subnacionais e da sociedade civil (BONDUKI, 2009; KRAUSE; BALBIN; NETO, 2013).

Para além da construção das moradias, alguns dos principais benefícios da autogestão são: a apropriação do espaço por parte dos futuros moradores e diversos ganhos relacionais e emancipatórios que uma organização deste tipo pode proporcionar. "A autogestão há mais de três décadas compõe uma das principais bandeiras de luta das organizações que compõem o movimento nacional de moradia" (TATAGIBA et al., 2013).

Todas as 11 entidades ouvidas pela pesquisa afirmaram organizar assembleias ou reuniões com frequência. A maioria delas diz dispor de pessoas para fazer o acompanhamento das condições de pagamento e ocupação das moradias, no entanto a ocupação adequada dos imóveis mostrou-se uma grande preocupação da Caixa, nas entrevistas com seus dirigentes.

O aprimoramento do Programa no sentido de aproximação da lógica de finanças da proximidade poderia aumentar o seu potencial em exercer algumas de suas expectativas centrais. A saber: A) fortalecimento dos movimentos de moradia e da rede de políticas públicas a eles associadas; B) aumento da relação de identificação entre o morador, sua casa e seu condomínio, propiciando maior qualidade das unidades e maiores potencialidades de empoderamento daquela comunidade; C) diminuição da inadimplência; D) aumento do controle social; E) desenvolvimento de capacidades de construção de direitos e relações de bem-estar social (TATAGIBA et al., 2013). Nesta mesma direção, as experiências sociais experimentadas no âmbito do PMCMV-Entidades poderiam ser expandidas e fomentadas nas outras modalidades do Programa, como também salienta um dirigente da Caixa com larga experiência na gestão de políticas habitacionais para a população de menor renda.

Essa parte de organização, de capacidade de mobilização e de reuniões é importante. (...) Na mobilização, na discussão com a prefeitura, na discussão de demandas de pessoas em situação de risco. É o que eu acho que poderia acontecer, já o resto (do que acontece aqui no Entidades) acho que é mais específico (Entrevista com dirigente $Y$, realizada em 12/11/2014).

Sobre o foco nas mulheres esta já é uma orientação que tem preocupado os formuladores do Programa, no entanto ainda é um desafio latente. Segundo dados da Caixa de 13/11/2014, cerca de 52,8\% dos contratos do PMCMV são assinados em nome 
das mulheres. Este percentual é um avanço em relação à lógica da política habitacional no Brasil. A Lei 11.124/05 (Lei de Criação do Sistema Nacional de Habitação de Interesse Social) estabelece no artigo 23 que o título da posse deve ser emitido preferencialmente no nome da mulher. Antes dela mesmo as políticas públicas de habitação reproduziam o viés de poder patriarcal, ao definir o a titularidade ao chefe da família. "Como a maioria dos(as) chefes eram homens, mesmo nos casos em que estes não eram provedores do sustento do lar, então o título, na maioria das vezes, estava no nome do homem" (LIMA, 2012).

Ainda que o PMCMV se baseie no referido critério da lei supracitada o percentual de $52,8 \%$ ainda é baixo para uma política pública com foco em gênero, remetendo-nos à ideia de que a orientação de gênero no Programa está mais no âmbito normativo do que positivo, principalmente quando a comparamos com outras políticas sociais de mesmo foco, entre elas o Programa Bolsa Família, no qual 93\% dos benefícios estão em titularidade de mulheres. Restam, pois, inúmeros desafios a serem enfrentados pelos formuladores e executores da política neste caminho.

\section{CONCLUSÕES E DESDOBRAMENTOS}

Identificamos potencial relevante de melhoria no processo de administração de risco de crédito dentro do PMCMV, especificamente na Faixa 1. Por ser destinada à população de renda mais baixa, dentro do Programa há certa tendência de aproximação com as inovações trazidas pelo microcrédito. As conclusões, nesse sentido, sobre o PMCMV em geral e sobre o PMCMV-E são as seguintes:

I. Ausência de mecanismos ex-ante que sejam capazes de selecionar adequadamente os beneficiários e enquadrá-los em uma faixa condizente de pagamento. Há forte incentivo para que todos, dentro da Faixa 1, paguem o valor mínimo de $\mathrm{R} \$ 25,00$.

II. A Faixa 1 é tratada preponderantemente como subsídio, não como uma modalidade de crédito ou financiamento: as maiores preocupações dos operadores do Programa têm sido a produção e entrega do imóvel. A expectativa sobre os pagamentos é secundária. Justamente ligada a isso, a trajetória recente dos dados de inadimplência é altamente desfavorável, especificamente na Faixa 1. Provavelmente, tal fato relaciona-se à sinalização adversa do Programa, cujo desenho engendra situações típicas de risco moral. Ou seja, para efeitos práticos, há pouca preocupação com inadimplência e os recursos estão associados mais à doação e menos a crédito.

III. Após a entrega do imóvel, há poucos instrumentos de acompanhamento das condições de pagamento dos beneficiários, ou seja, falta tecnologia de crédito baseada na proximidade que capture razoavelmente a dinâmica da vida financeira dos beneficiários.

IV. A utilização de agentes de crédito, nos moldes de diversos modelos de microcrédito, poderia contribuir para mitigar o risco de crédito, sobretudo pela proximidade com os beneficiários.

V. É possível aperfeiçoar o uso de informações e complementar bancos de dados disponíveis, com informações locais, geralmente informais. 
VI. Verifica-se baixa focalização de gênero: a despeito dos dispositivos legais a respeito (Lei 11.124/05), o total de contratos do PMCMV em titularidade de mulheres é de 52,8\% (para os contratos celebrados com a Caixa), o que é muito baixo se comparado a outras políticas sociais federais com foco em gênero, embora seja razoavelmente exitoso para um programa habitacional.

VII. Baixo envolvimento das entidades em ações de controle da inadimplência. Caso do bônus de adimplência a ser repassado às entidades, que não tem sido efetivado. Com isso, perde-se potencial de utilização de informações locais, com efeitos sobre a inadimplência.

VIII. Não efetivação do aval solidário, que embora seja uma forma de garantia prevista na lei, ainda não foi utilizado em nenhum contrato do PMCMV-E.

Em suma, as tecnologias empregadas no microcrédito podem ser úteis para aumentar a participação social na política pública e consolidar mecanismos de seleção e acompanhamento dos financiamentos. Muitas destes princípios já estão previstos no desenho formal do Programa, mas enfrentam uma série de óbices para sua efetivação.

Destacamos, assim, uma vasta agenda de pesquisa sobre o PMCMV. Este trabalho apenas serve de prospecção e apontamento da importância de novos estudos que tragam as problemáticas das efetivas viabilidades técnica e política da adoção de mecanismos estratégicos de microcrédito, ou ainda, estudos quantitativos sobre mecanismos e seu impacto sobre o comportamento da inadimplência.

\section{REFERÊNCIAS}

AGHION, B. A.; MORDUCH, J. The Economics of Microfinance. Cambridge, MA: The MIT Press, 2010.

AGIER, I. The role of credit officers in the performance of micro loans: Evidence from Brazil. Economics of Transition, vol. 20(2), p. 271-297, 2012.

AZEVEDO, S. Vinte e dois anos de política de habitação popular (1964-86): criação, trajetória e extinção do BNH. Revista de Administração Pública, Rio de Janeiro, v. 22, n. 4, p. 107-119, out./dez. 1988.

AZEVEDO, S. Desafios da habitação popular no Brasil: políticas recentes e tendências. In: ARRETCHE, M. Relações federativas nas políticas sociais. Educação e sociedade, Campinas, v. 23, n. 80, p. 25-48, set. 2002.

BESLEY, T.; COATE, S. Group Lending, repayment incentives and social collateral. Journal of Development Economics, vol. 46 (1), p. 1-18, 1995.

BONDUKI, N. Do Projeto Moradia ao programa Minha Casa Minha Vida. Teoria e Debate, São Paulo, n. 82, maio/jun. 2009.

BONDUKI, N. Política habitacional e inclusão social no Brasil: revisão histórica e novas perspectivas no governo Lula. Arq. Urb., n. 1, 2008.

CAIXA ECONÔMICA FEDERAL (CEF). Demanda habitacional no Brasil. Brasília: Caixa Econômica Federal, 2013.

CAOUTTE, J.; ALTMAN, E. Managing Credit Risk: The Great Challenge for Global Financial Markets. Hoboken, New Jersey: John Wiley \& Sons, Inc., 2008.

DO LAGO, L. C. Autogestão da moradia na superação da periferia urbana: conflitos e avanços. Revista E-metropolis, Rio de Janeiro, n. 5, ano 2, 2011. Rio de Janeiro: Observatório das Metrópoles, 2011.

FEIGENBERG, B. et al. The economic returns to social interaction: Experimental evidence from microfinance. Harvard: Harvard University, 2011.

FERREIRA, R. F. C. F. Movimentos de moradia, autogestão e política habitacional no Brasil: do acesso à moradia ao direito à cidade. Buenos Aires: Congresso ISA, 2012.

GOMIDE, A. A.; SILVA, F.; PIRES, R. R. C. Capacidades estatais e políticas públicas: passado, presente e futuro da ação governamental para o desenvolvimento. In: IPEA. Brasil em desenvolvimento: Estado, planejamento e políticas públicas. Brasília: Ipea, 2014. 
GONZALEZ, L.; PIZA, C.; GARCIA, D. Sinergia entre microsseguro e microcrédito e o crescimento dos mercados no Brasil. Revista Brasileira de Risco e Seguro, vol. 5, n. 10, p. 45-84, 2009.

KRAUSE, C.; BALBIN, R.; NETO, V. C. L. Minha Casa, Minha Vida, nosso crescimento: onde fica a política habitacional. Brasília, RJ: IPEA, 2013. (Texto para discussão ).

LIMA, D. F. A. A política de titularidade residencial feminina no contexto da política habitacional. 2012. Dissertação (Mestrado em Políticas Públicas e Sociedade) - Universidade Estadual do Ceará, Fortaleza, 2012.

LOUREIRO, M.; MACARIO, V.; GUERRA, P. Democracia, arenas decisórias e políticas públicas: o Programa Minha Casa Minha Vida. Brasília; Rio de Janeiro: Instituto de Pesquisa Econômica Aplicada, 2013. (Texto para discussão).

MARQUES, E.; RODRIGUES, L. O Programa Minha Casa Minha Vida na metrópole paulistana: atendimento habitacional e padrões de segregação. Revista Brasileira de Estudos Urbanos e Regionais, v. 15, n. 2, p. 159-177, 2013.

MOH'D AL-AZZAM, A. R.; CARTER, H. B.; SUDIPTA, S. Repayment performance in group lending: Evidence from Jordan. Journal of Development Economics, 97, p. 404-414, 2012.

MORDUCH, J. The Microfinance Promise. Journal of Economic Literature, v. 37, n. 4, p. 1.569-1.614, 1999. MPOG. Ministério do Planejamento Orçamento e Gestão. Programa Minha Casa Minha Vida, 2013. (Apresentação da ministra em encontro junto a Secovi em 15/7/2013).

RODRIGUES, E. A estratégia fundiária dos movimentos populares na produção autogestionária da moradia. 2013. Dissertação (Mestrado) - Faculdade de Arquitetura e Urbanismo, USP, São Paulo, 2013.

SILVA, F. L. Coordenação governamental no presidencialismo de coalizão brasileiro: estudo de caso sobre o Ministério das Cidades no Governo Lula. 2014. Dissertação (Mestrado do Programa de Pós-Graduação em Administração Pública e Governo) - FGV, São Paulo, 2014.

SILVA, L. A. L. A construção federal da intersetorialidade na política de desenvolvimento social brasileira: o caso do programa Bolsa Família. 2013. Dissertação (Mestrado) - Universidade Federal de São Carlos, UFSCar, Programa de Pós-Graduação em Ciência Política, São Carlos, 2013.

STIGLITZ, J. Peer Monitoring and credit markets. The World Bank Economic Review, vol. 4, n. 3, p. 351366,1990

TATAGIBA, L. F. et al. Inovações participativas nas políticas habitacionais para população de baixa renda: um estudo de caso sobre o Programa Minha Casa, Minha Vida - Entidades. Relatório de Pesquisa: Programa Regional de Becas de Investigación Clacso-ASDI. Campinas, SP; Nepac; Unicamp, 2013.

VARIAN, H. Monitoring agents with other agents. Journal of Institutional and Theoretical Economics, vol. 146, n. 1, p. 153-174, Mar. 1990.

WARTCHOW, J. A autogestão da produção habitacional como acesso alternativo à moradia. A experiência da cooperativa dos Correios na Região Metropolitana de Porto Alegre. 2012. Dissertação (Mestrado) Programa de Pós-Graduação em Planejamento Urbano e Regional. Porto Alegre: UFRGS, 2012. 